\title{
Clinical presentation of abdominal tuberculosis in HIV seronegative adults
}

\author{
Cengiz Bolukbas*1, Fusun F Bolukbas¹, Tulin Kendir², Remzi A Dalay², \\ Nihat Akbayir ${ }^{3}$, Mehmet H Sokmen ${ }^{3}$, Ali T Ince ${ }^{2}$, Mithat Guran ${ }^{4}$, \\ Erkan Ceylan ${ }^{5}$, Guray Kilic ${ }^{6}$ and Oya Ovunc ${ }^{2}$
}

\begin{abstract}
Address: ${ }^{1}$ Department of Internal Medicine, Gastroenterology Division, Faculty of Medicine, Harran University, Sanliurfa, Turkey, ${ }^{2}$ Gastroenterology Clinic, Haydarpasa Numune Training and Research Hospital, Istanbul, Turkey, ${ }^{3}$ Gastroenterology Clinic, Sisli Etfal Training and Research Hospital, Istanbul, Turkey, ${ }^{4}$ General Surgery Clinic, Haydarpasa Numune Training and Research Hospital, Istanbul, Turkey, ${ }^{5}$ Department of Chest Diseases, Faculty of Medicine, Harran University, Sanliurfa, Turkey and 'Pathology Unit, Haydarpasa Numune Training and Research Hospital, Istanbul, Turkey
\end{abstract}

Email: Cengiz Bolukbas* - drcengizbolukbas@hotmail.com; Fusun F Bolukbas - fusunbol@yahoo.ca; Tulin Kendir - eylul19@hotmail.com; Remzi A Dalay - remzidalay@att.net; Nihat Akbayir - akbayirn@hotmail.com; Mehmet H Sokmen - hmsokmen@hotmail.com; Ali T Ince - alince@superonline.com; Mithat Guran - mithatguran@yahoo.com; Erkan Ceylan - drerkanceylan@yahoo.com; Guray Kilic - gurayk61@hotmail.com; Oya Ovunc - oyaovunc@hotmail.com

* Corresponding author

\section{Published: 21 June 2005}

BMC Gastroenterology 2005, 5:21 doi:|0.1 186/147|-230X-5-21
Received: 23 February 2005

Accepted: 21 June 2005

This article is available from: http://www.biomedcentral.com/I47I-230X/5/2I

(C) 2005 Bolukbas et al; licensee BioMed Central Ltd.

This is an Open Access article distributed under the terms of the Creative Commons Attribution License (http://creativecommons.org/licenses/by/2.0), which permits unrestricted use, distribution, and reproduction in any medium, provided the original work is properly cited.

\begin{abstract}
Background: The accurate diagnosis of abdominal tuberculosis usually takes a long time and requires a high index of suspicion in clinic practice. Eighty-eight immune-competent patients with abdominal tuberculosis were grouped according to symptoms at presentation and followed prospectively in order to investigate the effect of symptomatic presentation on clinical diagnosis and prognosis.
\end{abstract}

Methods: Based upon the clinical presentation, the patients were divided into groups such as non-specific abdominal pain \& less prominent in bowel habit, ascites, alteration in bowel habit, acute abdomen and others. Demographic, clinical and laboratory features, coexistence of pulmonary tuberculosis, diagnostic procedures, definitive diagnostic tests, need for surgical therapy, and response to treatment were assessed in each group.

Results: According to clinical presentation, five groups were constituted as non-specific abdominal pain $(n=24)$, ascites $(n=24)$, bowel habit alteration $(n=22)$, acute abdomen $(n=9)$ and others $(n=9)$. Patients presenting with acute abdomen had significantly higher white blood cell counts $(p=0.002)$ and abnormalities in abdominal plain radiographs $(p=0.014)$. Patients presenting with alteration in bowel habit were younger $(p=0.048)$. The frequency of colonoscopic abnormalities $(7.5 \%)$, and need for therapeutic surgery $(12.5 \%)$ were lower in patients with ascites, $(p=0.04)$ and $(p=0.001)$, respectively. There was no difference in gender, disease duration, diagnostic modalities, response to treatment, period to initial response, and mortality between groups $(p>0.05)$. Gastrointestinal tract alone was the most frequently involved part (38.5\%), and this was associated with acid-fast bacteria in the sputum $(p=0.003)$.

Conclusion: Gastrointestinal tract involvement is frequent in patients with active pulmonary tuberculosis. Although different clinical presentations of patients with abdominal tuberculosis determine diagnostic work up and need for therapeutic surgery, evidence based diagnosis and consequences of the disease does not change. 


\section{Background}

Tuberculosis (TB) is rarely seen in western countries, but it is not an uncommon disease in the developing world [1]. Its reappearance has increased in association with the acquired immunodeficiency syndrome (AIDS) and immigration to the United States [2-4]. TB in its various forms remains an important cause of morbidity and mortality in developing countries and in patients with AIDS [5].

Recently, along with the increased incidence of TB, extrapulmonary TB incidence has also increased [6,7]. The occurrence of abdominal TB is independent of pulmonary disease in most patients, with a reported incidence of coexisting disease varying from 5 to $36 \%$ [8]. In patients with abdominal $\mathrm{TB}$, the highest incidence of disease was noted in the gastrointestinal tract and in the peritoneum, followed by the mesenteric lymph nodes. Within the gastrointestinal tract, the ileocecal area is the most common site of involvement [9].

In general, upper gastrointestinal (GI), hepatic and pancreatic involvements are rare in autopsy series and case reports [10-12].

Because of chronic and nonspecific clinical and radiological findings mimicking several diseases, such as Crohn's disease, carcinoma, sarcoma [13], amebiasis, yersinia infection, gastrointestinal histoplasmosis, and periappendiceal abscess [9], the diagnosis of the abdominal TB requires a high index of suspicion and, despite using newly developed diagnostic tools, it usually takes a long time to get accurate diagnosis in clinic practice. The patients' subjective complaints on admission should guide the diagnostic procedures [14].

In this report, the effect of different clinical presentations of abdominal TB on clinical course, diagnosis and outcome of the disease in 88 immune-competent patients who were grouped according to the gastrointestinal symptoms at admission and followed prospectively between 1995 and 2004.

\section{Methods}

Patients, who were suspected to have abdominal tuberculosis through symptoms and / or operative findings, were prospectively evaluated. In addition to physical examination, basic laboratory studies, and anti-human immunodeficiency virus (HIV) serology, patients admitted with abdominal symptoms including pain, distension, nausea, vomiting, altered bowel habit, weight loss were evaluated for tuberculosis. Previous and family histories of TB were asked; chest X-ray, abdominal plain graph, tuberculin skin test and abdominal ultrasound (US) were routinely obtained during a nine-year period between 1995-2004. In case of suggestion of pulmonary TB in chest $\mathrm{x}$-ray (infil- tration or consolidation, nodularity, calcification, cavitary lesion, and fibrocalcific scar in lung parenchyma, pleural effusion, hilar or mediastinal lymphadenopathy), acidfast bacilli (AFB) was searched in sputum and/or gastric juice. Sputum culture, and computed tomography (CT) of thorax were obtained. In case of negative results, bronchoscopy, and bronchoalveolar lavage plus biopsy were performed. If there was mediastinal lymphadenopathy (LAP) and the exact diagnosis could not be established by other means, mediastinoscopy with LAP biopsy was performed.

Based upon the clinical presentation, the patients were divided into five groups to guide diagnostic evaluations.

Group I: Patients with non-specific abdominal pain

\section{Group II: Patients with ascites}

Group III: Alteration in bowel habit (diarrhea, constipation or together)

Group IV: Acute Abdomen

Group V: Others (jaundice, dysphagia, fistula, fever of unknown origin, mass, weight loss)

Group I patients: abdominal CT, and according to the findings of CT, fine needle aspiration (FNA) biopsy or laparoscopy, upper and lower GI system endoscopy, and endoscopic biopsy for microbiologic and histopathologic diagnosis if a lesion seen.

Group II patients: ascitic cell count and type of cells, biochemistry analysis, smear for AFB, culture, IS6110-based in-house polymerase chain reaction (PCR) protocol for mycobacterium tuberculosis, and cytologic examination of ascitic fluid and abdominal CT.

Group III patients: colonoscopy and small bowel series, stool culture and AFB in stool if diarrhea present. Endoscopic biopsy for histopathologic examination and tissue culture and PCR for M. tuberculosis. Abdominal CT, and US. If ascites found, the exaimations in group II.

Group IV patients: histopathologic examination of surgical specimen if laparotomy performed. Abdominal CT, and colonoscopy if the patient is conservatively observed.

Group V patients: Upper endoscopy and thoraco-abdominal CT if dysphagia is present. Liver biopsy after excluding other causes if jaundice is present. Abdominal CT and if necessary MR and FNA in cases with abdominal mass were done. In patients with fistula only, AFB, culture and PCR of flux material; fistulography, CT, barium series or 
endoscopic examinations are performed to find out fistula tract.

Intraabdominal fluid (free or loculated; clear or complex with septae or debri), inter loop ascitis such as 'club sandwich' or 'sliced bread' signs which are due to localized fluid between radially oriented bowel loops, due to local exudation from the inflammed bowel, lymphadenopathy (discrete or conglomerated), bowel wall thickening and pseudo kidney sign were attributed to abdominal TB in abdominal US $[15,16]$. CT findings include adenopathy with low-density in centers, splenomegaly and hepatomegaly with nodules, ascites with complex features, bowel involvement, pleural effusion, intrasplenic, intrahepatic and intrapancreatic masses [8]. The colonoscopic features were defined as ulcers, nodules, deformed cecum and ileocecal valve, strictures, multiple fibrous bands and polypoid lesions [17].

Definitive diagnosis was based on one of the following methods with certain criteria: First of all, diagnostic priority for TB was given to show AFB microbiologically by culture or by both smear and PCR positivities, if that was not possible, the presence of caseating granulomatous lesions in the tissue was accepted as histopathological diagnosis of TB. If the diagnosis of TB was not obtained by using both of these methods, we achieved a clinical diagnosis of TB after a successful empiric therapeutic trial $[9,18]$. Empiric therapeutic trial was conducted for at least for 3 months with standard four drugs regiment (isonicotinic acid hydrazide, rifampin, pyrazinamide and ethambutol or streptomycin).

The following features were determined within each patient group: age, gender, disease duration, symptom frequency, TB presence in patient's history or environment, coexistence with pulmonary $\mathrm{TB}$, tuberculin skin test status, laboratory findings, diseased segment within gastrointestinal segment, necessary diagnostic work-up, exact diagnosis methods, need for surgery except acute abdomen, response to therapy. The patients were followed up for adverse effects of medical treatment and surgical complications.

Numeric values were determined as percent or mean \pm SD. Non-parametric Kruskal-Wallis test was used for quantitative results and chi-square test was used for qualitative results between groups. P value of less than 0.05 was considered to indicate the statistical significance.
Table I: Demographic and clinic features in whole group.

\begin{tabular}{ll}
\hline Patients, (n) & 88 \\
\hline Age (year) & $31.4 \pm 15$ \\
\hline Gender (F/M) & $48 / 40$ \\
\hline Disease duration (month) & $10.4 \pm 19$ \\
\hline Main symptom (n/\%) & \\
Abdominal pain & $25(28.4 \%)$ \\
Abdominal distension & $23(26.1 \%)$ \\
Diarrhea & $15(17 \%)$ \\
Fever & $4(4.5 \%)$ \\
Weight loss & $4(4.5 \%)$ \\
Ileus & $4(4.5 \%)$ \\
Perforation & $4(4.5 \%)$ \\
Others & $4(4.5 \%)$ \\
Dysphagia & $2(2.3 \%)$ \\
Icter & $2(2.3 \%)$ \\
Dyspepsia & $1(1.1 \%)$ \\
\hline Previous history for TB & $15(17 \%)$ \\
\hline Family history for TB & $8(9.1 \%)$ \\
\hline
\end{tabular}

F, Female; M, Male; TB, Tuberculosis.

Table 2: The results of the diagnostic methods in whole group.

\begin{tabular}{|c|c|}
\hline $\operatorname{ESR}(\mathrm{mm} / \mathrm{h})$ & $68 \pm 24$ \\
\hline $\mathrm{CRP}(\mathrm{mg} / \mathrm{L})$ & $53 \pm 39$ \\
\hline $\mathrm{WBC}\left(/ \mathrm{mm}^{3} \times 1000\right)$ & $9.2 \pm 3.6$ \\
\hline Hct \% & $32.3 \pm 5.2$ \\
\hline $\mathrm{Hb}(\mathrm{g} / \mathrm{dL})$ & $10.6 \pm 1.9$ \\
\hline \multicolumn{2}{|l|}{ Chest X-ray \% } \\
\hline Active lesion & $24(27.3 \%)$ \\
\hline Lesion consistent with prior TB & $15(17 \%)$ \\
\hline Normal & $49(55.7 \%)$ \\
\hline AFB positivity in sputum $\%$ & II (I2.6\%) \\
\hline $\begin{array}{l}\text { Lesion frequency in abdominal } \\
\text { plain graphs \% }\end{array}$ & $21(23.9 \%)$ \\
\hline Abdominal US abnormality* & $78(88.6 \%)$ \\
\hline
\end{tabular}

*Including hepatomegaly-splenomegaly

ESR, erythrocyte sedimentation rate; CRP, C-reactive protein; WBC, white blood cell count:

Hct, haemotocrit; Hb, haemoglobin; AFB, acid-fast bacteria; US, ultrasonography. 
Table 3: Demographic and clinical features in divided groups based upon the clinical presentation.

\begin{tabular}{|c|c|c|c|c|c|c|}
\hline Groups* & $I(n=24)$ & II $(n=24)$ & III $(n=22)$ & $I V(n=9)$ & $V(n=9)$ & $P$ \\
\hline Age $(y r)$ & $36.5 \pm 20$ & $30.4 \pm 13$ & $23.5 \pm 8$ & $32.7 \pm 12$ & $38 \pm 16$ & 0.048 \\
\hline Gender (F/M) & $12 / 12$ & $|3 /| \mid$ & $14 / 8$ & $2 / 7$ & $5 / 4$ & 0.34 \\
\hline Disease Duration (mo) & $11.3 \pm 23$ & $6 \pm 8$ & $9.8 \pm 14$ & $25 \pm 41$ & $6.6 \pm 5$ & 0.869 \\
\hline Previous history of TB \% & 16.7 & 8.3 & 18.2 & 22.2 & 33.3 & 0.530 \\
\hline Family history for TB \% & 8.3 & 4.2 & 18.2 & II.I & 0 & 0.425 \\
\hline Weight loss (kg) & $8.2 \pm 7$ & $6 \pm 4.5$ & $8.5 \pm 6$ & $8.7 \pm 5$ & $8.1 \pm 7.2$ & 0.496 \\
\hline Temperature $\left({ }^{\circ} \mathrm{C}\right)$ & $37.5 \pm 1$ & $37.4 \pm 0.8$ & $37.5 \pm 1$ & $37.9 \pm 0.9$ & $37.2 \pm 1$ & 0.615 \\
\hline Fistula (\%)* & 8.3 & 0 & 31.8 & 0 & 22.2 & 0.07 \\
\hline Therapeutic Operation \% & 33.3 & 12.5 & 27.3 & 66.6 & 22.2 & 0.001 \\
\hline Response to therapy $\%$ & 91.7 & 95.8 & 90.9 & 77.7 & 100 & 0.354 \\
\hline First response to therapy (mo) & $2.5 \pm 1.5$ & $2.1 \pm 1.6$ & $1.9 \pm 1.3$ & $2.6 \pm 1.5$ & $2.8 \pm 2$ & 0.298 \\
\hline Death \% & 8.3 & 4.2 & 4.5 & II.I & 0 & 0.825 \\
\hline
\end{tabular}

*Group I, non-specific abdominal pain; Group II, ascites; Group III, alteration in bowel habit (diarrhea, constipation or together); Group IV, acute abdomen; Group V, others (jaundice, dysphagia, fistula, fever of unknown origin, mass, weight loss);

Yr, year; F, female; M, male; Mo, month; TB, tuberculosis.

$P$ value of less than 0.05 was considered to indicate the statistical significance in between groups.

\section{Results}

After extensive clinical, endoscopic, radiologic, microbiologic and histopathologic investigation, we identified and followed 88 abdominal TB cases with gastrointestinal involvement. Age, gender, and symptoms on admission are summarized in Table 1; laboratory, chest X-ray, abdominal plain film and US findings are summarized in Table 2.

The most frequent symptom was abdominal pain (28.4\%). TB was present in patient history and environment in 17 and 9.1 percent, respectively. Ascites was the most frequent physical finding (35.2\%). Other physical examination findings were hepatomegaly $(22.7 \%)$, splenomegaly (17\%), abdominal mass (17\%), fistula (12.5\%), peripheral LAP (11.4\%) and acute abdomen (10.2\%). Most of the patients were significantly anemic. Erythrocyte sedimentation rate (ESR) and C-reactive protein (CRP) were mostly elevated in the study group. ESR was normal only in 4 cases (4.5\%). Pulmonary active lesion or lesion consistent with prior TB were detected in 27.3 and 17 percent of the patients, respectively. There was significant association between AFB in sputum and GIS tract disease $(p=0.003)$. Ascites was detected in $40.9 \%$ of patients on US. On abdominal CT, besides ascites, gut wall thickness (frequently ileocecal region), LAP, abscess, and organomegaly etc. were detected in $81.8 \%$.

According to clinical presentation, five groups were constituted as non-specific abdominal pain $(\mathrm{n}=24)$, ascites $(\mathrm{n}=24)$, alteration in bowel habit $(\mathrm{n}=22)$, acute abdomen $(n=9)$, and others $(n=9)$. Age, gender, symptoms, need for surgery, diagnostic tests, how the diagnosis estab- lished (tissue and culture based against empiric), response to therapy according to the groups on admission are summarized in Table 3 and Table 4 . With excluding grouping symptoms, mean white blood cell count (WBC) and lesion frequency in plain abdomen graphy were higher in patients admitting with acute abdomen $(\mathrm{p}=0.002$ and $\mathrm{p}$ $=0.014$, respectively). Patients with alteration in bowel habit were statistically younger $(p=0.048)$. Abnormal finding frequency on abdominal CT was equal between groups ( $p=0.196)$. CT guided FNA biopsy was preformed in 10 patients and its diagnostic yield was $70 \%$ in these patients. Colonoscopic lesion frequency was the lowest $(7.5 \%)$ in colonoscopy-performed patients with ascites (p $=0.04)$. In our patients who had colonoscopic abnormalities, tissue culture and PCR positivity for TB was $11.1 \%$ and $19.2 \%$, respectively. Although need for surgery rates was not different between patient groups, therapeutic surgery rate was significantly low $(12.5 \%)$ in patients with ascites $(p=0.001)$. Gender, disease duration, associated symptoms, definitive diagnostic methods, response to therapy, time to response to therapy, and mortality were not different between groups ( $p>0.05)$.

The localization and the type of disease were shown in Table 5. Gastrointestinal tract alone was the most frequent diseased part $(38.5 \%)$ and iloececal region was the preferred area $(53.8 \%)$ in the tract. Peritoneal and GI tract involvement proportions were approximately equal in patients admitted with abdominal pain. Isolated involvement of peritoneum was $71 \%$ in patients with ascites. The involvement rate of GI tract alone was $72.7 \%$ in patients with alteration in bowel habit. All patients with acute abdomen had GI tract involvement. Solitary mesenteric 
Table 4: The results of the diagnostic laboratory methods, the rate of abnormality in imaging and invasive methods, and definitive diagnosis in divided groups based upon the clinical presentation.

\begin{tabular}{|c|c|c|c|c|c|c|}
\hline Groups* & $\mathrm{I}(\mathrm{n}=24)$ & II $(n=24)$ & III $(n=22)$ & $\mathrm{IV}(\mathrm{n}=9)$ & $V(n=9)$ & $P$ \\
\hline $\mathrm{WBC}(/ \mathrm{mm} 3 \times 1000)$ & $10 \pm 4$ & $8.7 \pm 2.6$ & $7.7 \pm 1.8$ & $14 \pm 3.7$ & $7.3 \pm 2.8$ & 0.002 \\
\hline $\operatorname{ESR}(\mathrm{mm} / \mathrm{h})$ & $67 \pm 21$ & $65 \pm 31$ & $71 \pm 20$ & $69 \pm 21$ & $72 \pm 26$ & 0.842 \\
\hline Tuberculin skin test $(\mathrm{mm})$ & $17 \pm 7$ & $18 \pm 6.5$ & $13 \pm 7$ & $18 \pm 11$ & $16 \pm 9$ & 0.119 \\
\hline AFB in sputum $\%$ & 12.5 & 4.5 & 18.2 & 25 & 11 & 0.602 \\
\hline Chest X-ray \% & 54.2 & 27.5 & 40.9 & 66.6 & 22.2 & 0.448 \\
\hline APG $\%$ & 20.8 & 12.5 & 31.8 & 66.7 & 0 & 0.014 \\
\hline Abdominal CT \% & 91.7 & 100 & 90.9 & 100 & 77.8 & 0.196 \\
\hline ** Colonoscopy \% & $62.5(5 / 8)$ & $7.5(2 / 15)$ & $90.9(20 / 22)$ & $75(3 / 4)$ & $33.3(1 / 3)$ & 0.04 \\
\hline Operation \% & 54.2 & 54.2 & 33.3 & 75 & 22.2 & 0.156 \\
\hline \multicolumn{7}{|l|}{ Diagnosis \% } \\
\hline Evidence based & 79.2 & 83.3 & 86.4 & 88.9 & 88.9 & \\
\hline Histopathologic & 62.5 & 50 & 45.5 & 44.4 & 55.6 & \\
\hline Microbiologic & 4.2 & 12.5 & 9.1 & 33.3 & II.I & 0.933 \\
\hline $\mathrm{H}+\mathrm{M}$ & 12.5 & 20.8 & 31.8 & 11.1 & 22.2 & \\
\hline ETT\% & 20.8 & 16.7 & 13.6 & 11.1 & II.I & \\
\hline
\end{tabular}

*Group I, non-specific abdominal pain; Group II, ascites; Group III, alteration in bowel habit (diarrhea or constipation or together); Group IV, acute abdomen; Group V, others (jaundice, dysphagia, fistula, fever of unknown origin, mass, weight loss);

** The percent in patients with colonoscopy performed WBC, white blood cell count; ESR, erythrocyte sedimentation rate; AFB, acid-fast bacteria; APG, abdominal plain graphy; $C T$, computed tomography; $\mathrm{H}$, histopathologic; $\mathrm{M}$, microbiologic; ETT, empiric therapeutic trial. $\mathrm{P}$ value of less than 0.05 was considered to indicate the statistical significance in between groups.

lymphadenitis $(0.5 \%)$, liver $(0.5 \%)$, pancreas $(0.5 \%)$ and esophagus $(0.5 \%)$ involvements were established.

In the whole group, tissue and culture based and empiric therapeutic trial diagnosis rates were 75.4 and 14.6 percent, respectively.

Peroperative mortality in 1 case, fistula in 3 cases, short bowel in 1 case, and chronic pancreatic insufficiency in 1 patient developed as complications.

\section{Discussion}

Patients with abdominal TB may have many symptoms and mimic many diseases, therefore if it is not clinically suspected, it may result in important morbidity and mortality. In abdominal TB series GI tract and peritoneum are reported as the most frequent sites of involvement [9]. Four major pathophysiologic mechanisms are proposed for abdominal TB: hematogenous spread, swallowing of infected sputum, ingestion of contaminated milk or food, and contiguous spread from adjacent organs [19].

In our patients, GI tract alone, peritoneum alone, and GI tract with peritoneum involvement (multi-site) were most frequent and detected in 38.5, 28, and 20.4 percent, respectively. Mesenteric lymph node involvement alone was rare, liver involvement was uncommon, but even esophageal and pancreatic involvement mimicking tumor was present.

The ileocecal area is the most frequent site of involvement in the GI tract $[9,20]$. Physiologic stasis, absorption of digested materials, and augmented lymphoid tissue at ileocecal area may be the causes of this property $[21,22]$. In our patients, GI tract and ileocecal region in particular, was also most frequently diseased part.

Gastroenterological symptoms of abdominal TB depend on the organ or tissue involved. Abdominal pain, tense- 
Table 5: The distribution of involvement area in the groups*.

\begin{tabular}{|c|c|c|c|c|c|c|}
\hline Localization & $\begin{array}{l}\text { Group I } \\
(n=24)\end{array}$ & $\begin{array}{l}\text { Group II } \\
(\mathrm{n}=24)\end{array}$ & $\begin{array}{l}\text { Group III } \\
(n=22)\end{array}$ & $\begin{array}{l}\text { Group IV } \\
(n=9)\end{array}$ & $\begin{array}{l}\text { Group V } \\
(n=9)\end{array}$ & $\begin{array}{l}\text { Total } \\
\text { (n) }\end{array}$ \\
\hline Multiple (n) (Peritoneum, SB, colon, pericardium) & 2 & 7 & 6 & I & 2 & 18 \\
\hline GI Tract (n) & & & & & & 34 \\
\hline SB & & & 3 & 2 & I & \\
\hline lleocecal & 6 & & 7 & 5 & & \\
\hline Colon & & & 6 & I & & \\
\hline Stomach & I & & & & & \\
\hline Esophagus & & & & & 2 & \\
\hline Liver & 3 & & & & 1 & 4 \\
\hline Peritoneum & 8 & 17 & & & & 25 \\
\hline Mesenteric LAP & 3 & & & & 2 & 5 \\
\hline Pancreas and biliary system & 1 & & & & 1 & 2 \\
\hline Total (n) & 24 & 24 & 22 & 9 & 9 & 88 \\
\hline
\end{tabular}

*Group I, non-specific abdominal pain; Group II, ascites; Group III, alteration in bowel habit (diarrhea or constipation or together); Group IV, acute abdomen; Group V, others (jaundice, dysphagia, fistula, fever of unknown origin, mass, weight loss);

$\mathrm{SB}$, small bowel; GI, gastrointestinal; LAP, lymphadenopathy

ness, and diarrhea, as our patients demonstrated, are frequent symptoms. Also, as reported in the literature, active TB lesion or lesion consistent with prior TB in the lungs are detected in 27.3 and 17 percent of the whole group of patients, respectively $[9,18]$. Diagnosis is difficult in the absence of pulmonary involvement. As a result, clinical and radiologic signs of pulmonary TB must be searched for in every patient even in the absence of pulmonary symptoms. Meantime, absence of pulmonary findings does not rule out abdominal TB.

As reported previously [14], subjective complaints of the patients could guide the diagnostic procedures. For this reason, to group the patients according to their symptoms on admission may cause the diagnostic work up to be more cost effective. When our patients are grouped according to symptoms, disease duration, gender, weight loss, fever, and previous or family history of TB were not different between groups. There was no significant difference in frequency of radiologic pulmonary lesions, tuberculin skin test status, and ESR or CRP elevation between groups. This observation has not been reported before.

Although WBC, and abdominal plain film abnormalities were higher in patients with acute abdomens, these findings were nonspecific for $\mathrm{TB}$ diagnosis. On the other hand, macroscopic findings and histopathologic and microbiologic investigations of the tissues obtained during therapeutic surgery made abdominal TB diagnosis eas- ier and faster in this specific patient group. Abdominal CT abnormalities regarding TB were observed in all patients with acute abdominal findings. This feature has given an opportunity to follow these patients, excluding those with perforation, with conservative medical treatment $[8,23]$. In this subgroup of patients colonoscopy during followup revealed abnormality in $75 \%$, and provided histopathologic and microbiologic TB diagnosis in 50\%.

Although both abdominal US and CT are equally sensitive in detecting ascites, CT is superior to US in detecting LAP, gut wall thickness, omental cake, and other abnormalities $[24,25]$. Abnormal abdominal CT findings in our series were higher than US findings and were equal in each group. CT shows localization and type of the lesion, but it is not specific for TB diagnosis $[26,27]$. CT guides the following diagnostic methods such as FNA, endoscopy, laparoscopy or laparotomy $[16,27]$.

Therapeutic and diagnostic surgery rates were similar between our patient groups. This may be due to two reasons. Firstly, ascites examination, FNA biopsy, and endoscopic methods may be inadequate for definitive diagnosis. Secondly, patients with abdominal pain or altered bowel habit groups may develop complications requiring surgery. Diagnostic laparotomy was needed most often in patients with ascites. Infrequent detection of AFB in ascitic fluid, late results of ascites cultures, and uncommon culture yield of $\mathrm{M}$. tuberculosis are reasons 
for increased laparoscopy/laparotomy need $[28,29]$. Diagnostic operation was lower in patients with alteration in bowel habit and the group in which GI tract was not directly involved. Endoscopic examinations increased diagnostic efficiency and decreased diagnostic surgical interventions in patients with alteration in bowel habit. Patients with acute abdominal symptoms frequently have GI tract and particularly ileocolonic involvement. Colonoscopy is effective to establish TB diagnosis in patients that could be managed medically in this group. Colonoscopy provides tissue for culture, PCR and histopathologic examination [30]. In our patients who had colonoscopic abnormalities, tissue culture and PCR positivity for TB rate was lower than or at most equal to previously reported series $[17,31,32]$. Low colonoscopic biopsy count and sample size may affect this result. Stool examination for $\mathrm{AFB}$ and culture for $\mathrm{TB}$ are proposed in the literature, but the association of GI TB with AFB in the sputum may cause misinterpretation [19].

AFB is searched for in the sputum and when necessary in gastric juice in our patients with pulmonary involvement. There was a positive association between AFB positivity in sputum and GI tract involvement. This association can be explained with swallowing infected sputum [19]. AFB in sputum rate was not different between groups; this can be explained by existence of GI tract involved patients in groups formed with patient symptomatology. Patients with alteration in bowel habit were younger as reported in the literature. Wig K and et al. reported that the maximum age incidence of intestinal tuberculosis was also 15 to 24 years [33]. The reason of the high incidence rate of intestinal tuberculosis in young population could be related to Peyer's patches which play a major role in intestinal immunity and are portals of entry for significant pathogens. Peyer's patches in the small intestine peaks at ages 15-25 and then declines with age [34].

There was no significant difference between evidence based diagnosis and response to therapy diagnosis in all groups.

Our diagnosis rate based on response to therapy was similar to the rates reported before [18]. There was no difference in evidence based and response to treatment diagnosis between our groups. There was also no difference in first response time to therapy between two diagnostic methods. Empiric therapeutic trial appears to be a useful method for rapid presumptive diagnosis and treatment of tuberculosis [35].

It is reported that there is no difference in response or relapse rates between 9 month and 18 month treatment times [36]. All our patients received therapy for 9 months and had a high cure rate. High cure and low relapse rates may be caused by immune competence of our patients and infrequency of primary drug resistance in this group. High adherence to therapy rate and low adverse effects of drugs to lower dose rate may influence secondary drug resistance.

Fistula, short bowel syndrome, and anastomosis leak are frequent complications of surgery performed in abdominal TB [37]. Our patients had similar complications.

\section{Conclusion}

Gastrointestinal tract involvement is frequent in patients with active pulmonary tuberculosis. Different clinical presentation of patients with abdominal TB involving GI system may determine the necessity of diagnostic or therapeutic surgical interventions, but evidence based diagnosis and prognosis are not influenced.

\section{Abbreviations}

TB, tuberculosis; AIDS, acquired immunodeficiency syndrome; GI, gastrointestinal; HIV, human immunodeficiency virus; US, ultrasound; $\mathrm{AFB}$, acid-fast bacilli; $\mathrm{CT}$, computed tomography; LAP, lymphadenopathy; PCR, polymerase chain reaction; FNA, fine needle aspiration; $\mathrm{ESR}$, erythrocyte sedimentation rate; CRP, C-reactive protein; WBC, white blood cell count;

\section{Competing interests}

The author(s) declare that they have no competing interests.

\section{Authors' contributions}

$\mathrm{CB}$ conceived of the study, and participated in its design and coordination. FFB, TK, NA, HMS, ATI, MG, EC and GK collected the samples and clinical data, and carried out the laboratory analysis. ARD and FFB conceived of the study and participated in the sequence alignment and drafted the manuscript. OO participated in study design and coordination and revised the manuscript critically for important intellectual content. All authors read and approved the final manuscript.

\section{References}

I. Shukla HS, Hughes LE: Abdominal tuberculosis in 1970s: a continuing problem. BrJ Surg 1978, 65(6):403-405.

2. Guth $A A, K i m U:$ The reappearance of abdominal tuberculosis. Surg Gynecol Obstet 1991, 172(6):432-436.

3. Snider DE Jr, Roper WL: The new tuberculosis. N EnglJ Med I992, 326(10):703-705.

4. Probert CS, Jayanthi V, Wicks AC, Carr-Locke DL, Garner P, Mayberry JF: Epidemiological study of abdominal tuberculosis among Indian migrants and the indigenous population of Leicester, 1972-1989. Gut 1992, 33(8): 1085-1088.

5. Aliyu MH, Salihu HM: Tuberculosis and HIV disease: two decades of a dual epidemic. Wien Klin Wochenschr 2003, II5(1920):685-697.

6. Das P, Shukla HS: Clinical diagnosis of abdominal tuberculosis. Br J Surg 1976, 63( I 2):94|-946. 
7. Louie E, Rice LB, Holzman RS: Tuberculosis in non-Haitian patients with acquired immunodeficiency syndrome. Chest 1986, 90(4):542-545.

8. Hulnick DH, Megibow AJ, Naidich DP, Hilton S, Cho KC, Balthazar EJ: Abdominal tuberculosis: CT evaluation. Radiology 1985, I57(I):199-204.

9. Marshall JB: Tuberculosis of the gastrointestinal tract and peritoneum. Am J Gastroenterol 1993, 88(7):989-999.

10. Auerbach O: Acute generalized military tuberculosis. $\mathrm{Am}\rfloor$ Pathol 1944, 20:121-136.

II. Leder RA, Low VH: Tuberculosis of the abdomen. Radiol Clin North Am 1995, 33(4):691-705.

12. Amarapurkar DN, Patel ND, Amarapurkar AD: Primary gastric tuberculosis - report of 5 cases. BMC Gastroenterol 2003, 3(I):6.

13. Howell JS, Knapton PJ: Ileo-caecal tuberculosis. Gut 1964 19:524-529.

14. Ebdrup L, Storgaard M, Jensen-Fangel S, Obel N: Ten years of extrapulmonary tuberculosis in a Danish university clinic. Scand J Infect Dis 2003, 35(4):244-246.

15. Kedar RP, Shah PP, Shivde RS, Malde HM: Sonographic findings in gastrointestinal and peritoneal tuberculosis. Clin Radiol 1994, 49(I):24-29.

16. Sharma MP, Bhatia V: Abdominal tuberculosis. Indian J Med Res 2004, I 20(4):305-3I5.

17. Misra SP, Misra V, Dwivedi M, Gupta SC: Colonic tuberculosis: clinical features, endoscopic appearance and management. J Gastroenterol Hepatol 1999, 14(7):723-729.

18. Khan MR, Khan IR, Pal KM: Diagnostic issues in abdominal tuberculosis. J Pak Med Assoc 200I, 5 I (4): I38-| 42.

19. Horvath KD, Whelan RL: Intestinal tuberculosis: Return of an old disease. Am J Gastroenterol 1998, 93(5):692-696.

20. Wadhwa N, Agarwal S, Mishra K: Reappraisal of abdominal tuberculosis. J Indian Med Assoc 2004, I02(I):3I-42.

21. Patel N, Amarapurkar D, Agal S, Baijal R, Kulshrestha P, Pramanik S, Gupte P: Gastrointestinal luminal tuberculosis: establishing the diagnosis. J Gastroenterol Hepatol 2004, I 9(I I): I 240-1246.

22. Moss JD, Knauer CM: Tuberculous enteritis: $A$ report of three patients. Gastroenterology 1973, 65(6):959-966.

23. Anand BS, Nanda R, Sachdev GK: Response of tuberculous stricture to antituberculous treatment. Gut 1988, 29(I):62-9.

24. Balthazar EJ, Gordon R, Hulnick D: lleocecal tuberculosis: $\mathbf{C T}$ and radiologic evaluation. $A J R A m$ J Roentgenol 1990, 154(3):499-503.

25. Suri S, Gupta $S$, Suri R: Computed tomography in abdominal tuberculosis. Br J Radiol I999, 72(853):92-98.

26. Koh DM, Burn PR, Mathews G, Nelson M, Healy JC: Abdominal computed tomographic findings of Mycobacterium tuberculosis and Mycobacterium avium intracellulare infection in HIV seropositive patients. Can Assoc Radiol J 2003, 54(I):45-50.

27. Buxi TB, Vohra RB, Sujatha Y, Chawla D, Byotra SP, Gupta PS, Dewan VK, Kanwar C: CT appearances in macronodular hepatosplenic tuberculosis: a review with five additional new cases. Comput Med Imaging Graph 1992, 16(6):38I-387.

28. Demir K, Okten A, Kaymakoglu S, Dincer D, Besisik F, Cevikbas U, Ozdil S, Bostas G, Mungan Z, Cakaloglu Y: Tuberculous peritonitis - reports of 26 cases, detailing diagnostic and therapeutic problems. Eur J Gastroenterol Hepatol 200I, I3(5):58I-585.

29. Ibrarullah M, Mohan A, Sarkari A, Srinivas M, Mishra A, Sundar TS: Abdominal tuberculosis: diagnosis by laparoscopy and colonoscopy. Trop Gastroenterol 2002, 23(3): 150-153.

30. Pulimod AB, Ramakrishna BS, Kurian G, Peter S, Patra S, Mathan VI, Mathan MM: Endoscopic mucosal biopsies are useful in distinguishing granulomatous colitis due to Crohn's disease from tuberculosis. Gut 1999, 45(4):537-54I.

3I. Singh V, Kumar P, Kamal J, Prakash V, Vaiphei K, Singh K: Clinicocolonoscopic profile of colonic tuberculosis. Am J Gastroenterol 1996, $91(3): 565-568$.

32. Pfaller MA: Application of new technology to the detection, identification, and antimicrobial susceptibility testing of mycobacteria. Am J Clin Pathol 1994, I 1 (3):329-37.

33. Wig KL, Chitkara NL, Gupta SP, Kishore K, Manchada RL: Ileocecal tuberculosis with particular reference to isolation of Mycobacterium tuberculosis. With a note on its relation to regional ileitis (Crohn's disease). Am Rev Resp Dis 1961, 84:169-178.
34. Van Kruiningen $H J$, West $A B$, Freda BJ, Holmes KA: Distribution of Peyer's patches in the distal ileum. Inflamm Bowel Dis 2002, 8(3): $180-185$.

35. Anglaret X, Saba J, Perronne C, Lacassin F, Longuet $P$, Leport $C$, Vilde $J L$ : Empiric antituberculosis treatment: benefits for earlier diagnosis and treatment of tuberculosis. Tuber Lung Dis 1994, 75(5):334-340.

36. Kim SG, Kim JS, Jung HC, Song IS: Is a 9-month treatment sufficient in tuberculous enterocolitis? A prospective, randomized, single-centre study. Aliment Pharmacol Ther 2003, 18(I):85-9I.

37. Ha HK, Ko GY, Yu ES, Yoon K, Hong WS, Kim HR, Jung HY, Yang $\mathrm{SK}$, Jee KN, Min YI, Auh YH: Intestinal tuberculosis with abdominal complications: radiologic and pathologic features. Abdom Imaging 1999, 24(I):32-38.

\section{Pre-publication history}

The pre-publication history for this paper can be accessed here:

\section{http://www.biomedcentral.com/1471-230X/5/21/pre} pub
Publish with Bio Med Central and every scientist can read your work free of charge

"BioMed Central will be the most significant development for disseminating the results of biomedical research in our lifetime. "

Sir Paul Nurse, Cancer Research UK

Your research papers will be:

- available free of charge to the entire biomedical community

- peer reviewed and published immediately upon acceptance

- cited in PubMed and archived on PubMed Central

- yours - you keep the copyright
BioMedcentral 